\title{
Desafios e perspectivas do diagnóstico da esquistossomose mansônica no Brasil: revisão de literatura
}

\author{
Challenges and prospects of mansonic schistosomosis diagnosis in Brazil: literature \\ review
}

Desafíos y perspectivas del diagnóstico de la schistosomosis de mansonic en Brasil: revisión de la literatura

Darlesson Geovani dos Santos Sousa ${ }^{1 *}$, Raimundo Leoberto Torres de Sousa ${ }^{2}$, Débora Ribeiro de Mesquita $^{3}$, Célia Mariza de Oliveira Guerra Álvares ${ }^{3}$, Matheus Pereira Barbosa ${ }^{3}$, Cleanto Luiz Maia Silva $^{3}$, Anangela Ravena da Silva Leal ${ }^{2}$, Kitawann Tayrone de Sousa Nunes Cardoso ${ }^{4}$, Paulo Sérgio da Paz Silva Filho ${ }^{5}$, Edson Lourenço da Silva ${ }^{6}$.

\section{RESUMO}

Objetivo: Compreender as dificuldades e perspectivas dos principais métodos de diagnóstico para esquistossomose mansônica utilizados no Brasil. Métodos: Revisão bibliográfica realizada através da PubMed-MEDLINE, da National Library of Medicine dos Estados Unidos da América, utilizando os descritores "esquistossomose", "diagnóstico" e "Brasil". Resultados: Após a busca utilizando os três descritores mencionados e a seleção tendo como base os critérios de inclusão foram obtidos 21 artigos, sendo que 12 destes não se encaixavam com a metodologia do tema proposto. Dessa forma, foram analisados e discutidos 9 artigos científicos nacionais e estrangeiros com a temática "diagnóstico da esquistossomose mansônica". Considerações finais: Após a leitura e interpretação do conteúdo de cada artigo selecionado, foi possível a identificação de diversos tipos de métodos que podem ser utilizados para diagnóstico da esquistossomose mansônica no Brasil. Os métodos coprológicos, imunológicos e moleculares estão surgindo e se mostram bastantes promissores para um diagnóstico bastante eficaz, portanto, espera-se que políticas públicas sejam desenvolvidas com o objetivo de se realizar um controle mais rigoroso da doença no país.

Palavras-chave: Esquistossomose, Diagnóstico, Brasil.

\begin{abstract}
Objective: To understand the difficulties and perspectives of the main diagnostic methods for schistosomiasis mansoni used in Brazil. Methods: Bibliographic review conducted through PubMed-MEDLINE, from the National Library of Medicine of the United States of America, using the descriptors "schistosomiasis", "diagnosis" and "Brazil". Results: After the search using the three mentioned descriptors and the selection based on the inclusion criteria, 21 articles were obtained, 12 of which did not fit with the methodology of the proposed theme. Thus, 9 national and foreign scientific articles with the theme "diagnosis of schistosomiasis mansoni" were analyzed and discussed. Final considerations: After reading and interpreting the content of each selected article, it was possible to identify several types of methods that can be used to diagnose schistosomiasis mansoni in Brazil. Coprological, immunological and molecular methods are emerging and are very promising for a very effective diagnosis, therefore, it is expected that public policies will be developed with the objective of carrying out stricter control of the disease in the country.
\end{abstract}

Keywords: Schistosomiasis, Diagnosis, Brazil.

\footnotetext{
${ }^{1}$ Instituto Oswaldo Cruz (FIOCRUZ), Teresina - PI. *E-mail: darlebio@hotmail.com

2 Instituto Oswaldo Cruz (FIOCRUZ), Rio de Janeiro - RJ.

3 Universidade Estadual do Piauí (UESPI), Teresina - PI.

${ }^{4}$ Universidade Federal do Piauí (UFPI), Teresina - PI.

${ }^{5}$ Faculdade Maurício de Nassau (UNINASSAU), Teresina - PI.

6 Instituto Federal do Piauí (IFPI), Picos - PI.
} 


\section{RESUMEN}

Objetivo: Comprender las dificultades y perspectivas de los principales métodos de diagnóstico para la esquistosomiasis mansoni utilizados en Brasil. Métodos: Revisión bibliográfica realizada a través de PubMedMEDLINE, de Biblioteca Nacional de Medicina de los Estados Unidos, utilizando los descriptores "esquistosomiasis", "diagnóstico" y "Brasil". Resultados: Después de buscar utilizando los tres descriptores mencionados y seleccionando según los criterios de inclusión, se obtuvieron 21 artículos, 12 de los cuales no se ajustaban a la metodología del tema propuesto. Así, 9 artículos científicos nacionales y extranjeros fueron analizados y discutidos con el tema "diagnóstico de esquistosomiasis mansoni". Consideraciones finales: Después de leer e interpretar el contenido de cada artículo seleccionado, fue posible identificar varios tipos de métodos que pueden usarse para el diagnóstico de la esquistosomiasis mansoni en Brasil. Están surgiendo métodos coprológicos, inmunológicos y moleculares y son muy prometedores para un diagnóstico muy efectivo, por lo que se espera que se desarrollen políticas públicas con el objetivo de un control más riguroso de la enfermedad en el país.

Palabras clave: Esquistosomiasis, Diagnóstico, Brasil.

\section{INTRODUÇÃO}

A esquistossomose mansônica, conhecida popularmente como "doença do caramujo" e/ou "barriga d'água" é uma parasitose provocada pelo trematódeo Schistosoma mansoni, que tem caramujos do gênero Biomphalaria como hospedeiros intermediários e o homem como hospedeiro definitivo. A doença se caracteriza por um quadro agudo ou crônico, muitas vezes assintomático, mas que pode se manifestar de uma forma mais grave, provocando óbito do hospedeiro (ROCHA TJM, et al., 2016).

Segundo estimativas da Organização Mundial de Saúde (OMS) a esquistossomose afeta cerca de 200 milhões de pessoas no mundo, ocorrendo em aproximadamente 78 países (CARVALHO OS, et al, 2018; SOUZA GGS e CERQUEIRA EJL, 2009). A doença ocorre de forma endêmica em grande parte do Brasil, acometendo entre 2,5 a 8 milhões de pessoas e provocando grande número de casos graves e óbitos, caracterizando-se como um grave problema de saúde pública no Brasil (BRASIL, 2014) sendo a maior prevalência na região nordeste, seguida da região sudeste (MASSARA CL, et al., 2016).

No Brasil, o surgimento de um programa para controle da doença surgiu em 1975, com a criação do Programa Especial de Controle da Esquistossomose (PECE), coordenado pela Superintendência de Campanhas de Saúde Pública (SUCAM), e a partir de 1980, o PECE passou a ser um programa regular do Ministério da Saúde, sendo denominado de Programa de Controle da Esquistossomose (PCE). A partir de 1999, as ações do PCE passaram a ser responsabilidade compartilhada entre municípios e estados (COSTA CS, et al., 2017).

O Sistema de Informação do Programa de Controle da Esquistossomose (SISPCE) foi criado em 1996 com o objetivo de reunir os dados em cada Estado e ter maior controle sobre o PCE. Os dados disponibilizados através dessa plataforma referem-se às atividades desenvolvidas pelo PCE em todos os municípios endêmicos, permitindo analisar a situação epidemiológica de cada localidade (BARBOSA CS e GOMES ECS, 2017).

Apesar de diversas irregularidades nos programas de controle da esquistossomose é inegável observar os diversos resultados positivos que alcançados em relação ao controle da doença no País. De acordo com três inquéritos nacionais sobre a prevalência da parasitose, observou-se uma diminuição do número de casos, principalmente após a década de 70 , pois a partir desse período foi iniciada a utilização da oxaminiquina, e posteriormente do praziquantel, droga mais segura para realizar o tratamento dos indivíduos positivos (BARBOSA CS e GOMES ECS, 2017).

O último inquérito nacional da Esquistossomose no Brasil, foi realizado durante os anos de 2010 a 2015 com 197.564 escolares de 7 a 17 anos, de ambos os sexos, das 26 Unidades da Federação e do Distrito Federal, e revelou que 194.900 estavam negativos e 2.664 estavam eliminando ovos do S. mansoni, cuja 
proporção de positivos foi de $0,99 \%$. Os dados deste inquérito revelaram o decréscimo da prevalência no País, comparando os dois primeiros inquéritos realizados durante os anos de (1949-1953) e (1975-1978), respectivamente, e foi possível verificar que a positividade passou de $10,09 \%$ para $9,24 \%$ e atualmente está em 1,79\% (BRASIL, 2018).

Tendo em vista que os sintomas da esquistossomose mansoni podem ser confundidos com os de outras parasitoses, o diagnóstico coproparasitológico se faz indispensável (TERRA MR, et al., 2018; MELO AGSM, et al., 2019). A técnica de Kato-Katz é a mais utilizada pelos programas de controle e recomendada pela OMS e se mostra eficiente em indivíduos com carga parasitária alta ou média, pois além de permitir a visualização dos ovos, é possível fornecer indicativos sobre a intensidade da infecção (BRASIL, 2018; MARINHO CC, et al., 2017).

Apesar de ser amplamente utilizado, o método possui sensibilidade limitada devido à variabilidade de ovos liberados nas fezes em áreas de baixa prevalência, no entanto, aumentar a quantidade de lâminas através dessa técnica, pode facilitar a sensibilidade, tonando o método mais confiável (VITORINO RR, et al., 2012).

Testes imunológicos como reação de fixação de complemento, imunofluorescência indireta e ELISA de captura são exemplos de técnicas que já foram empregadas para diagnóstico de diferentes formas de esquistossomose. Porém a positividade dos exames imunológicos não necessariamente indica que o indivíduo está positivo para o parasito, pois alguns anticorpos circulantes podem permanecer após a cura da doença (SIQUEIRA LMV, et al., 2015).

Métodos moleculares, como a técnica de reação em cadeia da polimerase (PCR), por exemplo, é realizada com base na amplificação de uma sequência de DNA para o diagnóstico de infecção de $S$. mansoni em caramujos, e foi adaptada para o diagnóstico da esquistossomose mansoni em humanos (SOUSA SRM, et al., 2019; GANDASEGUI J, et al., 2018). Realizar diagnóstico sorológico para a esquistossomose mansoni, assim como para outras parasitoses, continua sendo um verdadeiro desafio, principalmente pelo alto custo de reagentes e por requerer profissional especializado para sua condução.

No entanto, técnicas sorológicas como o POC-CCA (point-of-care circulating cathodic antigen) tem quebrado essas barreiras e sido utilizada em diversos inquéritos parasitológicos desenvolvidos no país. Em 2015, a OMS recomendou o uso de dois métodos combinados, POC-CCA e Kato-Katz, cujo objetivo é monitorar a eficiência dos programas de controle em países endêmicos (SOUSA SRM, 2019).

Outros métodos com mecanismos imunológicos envolvem a reação de antígeno-anticorpo e têm aplicação muitas vezes em inquéritos epidemiológicos, acompanhados ou não de exame coprológico. Podem ser utilizados em casos clínicos isolados, de diagnóstico difícil ou pelos métodos diretos tradicionais. Os principais são: ensaio imunoenzimático (ELISA), imunofluorescência (IF) e reação peri-ovular (RPOV) (NEVES DP, 2002).

O PCE segue duas abordagens para o combate da doença: i) controle da morbidade, cujo objetivo é a redução das formas graves da doença e ii) controle da transmissão através da interrupção do ciclo evolutivo do parasito (MARINHO CC, et al., 2017). Nessa última, estão inclusos o saneamento básico, o abastecimento de água potável, assim como a restrição da população em locais em que há constatação de caramujos infectados. Apesar de alguns programas terem suas atividades focadas no controle de moluscos, essa forma não é bastante sustentada, pois ocorre rapidamente o repovoamento dos moluscos nas coleções hídricas (SARVEL AK, et al., 2011).

O Ministério da Saúde preconiza como tratamento para esquistossomose o uso do Praziquantel em comprimido de $600 \mathrm{mg}$. Para crianças, a dose é de $60 \mathrm{mg} / \mathrm{kg}$ de peso em dose única por via oral após a refeição e em adultos, a dose é de $50 \mathrm{mg} / \mathrm{kg}$ de peso. Juntamente com esse tratamento ocorre a Campanha Nacional de Hanseníase, Verminoses, Tracoma e Esquistossomose, cujo principal objetivo é reduzir a carga parasitária de geo-helmintíases em escolares na faixa etária de 5 a 14 anos da rede pública municipal de ensino através do uso de Albendazol $400 \mathrm{mg}$. Essa forma de combate visa a realizar a redução dos custos do tratamento e intensificar os resultados do controle, pois a escola é um ambiente que abriga uma grande quantidade de indivíduos (SIQUEIRA LMV, 2015; BRASIL, 2017). 
Apesar da existência de programas de controle, diversos estudos têm demonstrado a expansão das áreas de transmissão, e mudanças do perfil rural para urbano da doença (MOURA BRS, et al., 2018; GOMES ECS, et al., 2016; DEININGER LSC, et al., 2018). Dessa forma, é necessário o conhecimento sobre a prevalência atual da doença para subsidiar as atividades de prevenção e tratamento, descrever os fatores associados à transmissão e também determinar o montante de recursos que serão adequados para o planejamento e das ações de vigilância e controle (BRASIL, 2018).

Diante do que foi exposto, esse estudo tem como objetivo descrever as dificuldades e perspectivas acerca dos principais métodos utilizados para diagnosticar a esquistossomose mansônica no Brasil.

\section{MÉTODOS}

Os procedimentos metodológicos desse estudo se caracterizam pela revisão integrativa de literatura, buscando compreender as dificuldades e perspectivas dos principais métodos de diagnóstico para esquistossomose mansônica utilizados no Brasil. As etapas que compõem esta revisão integrativa são: escolha e definição do tema proposto, busca na base de dados, análise da produção científica que atenda os critérios de inclusão e exclusão, definição das informações que serão extraídas, análise de dados e apresentação dos resultados.

A revisão de literatura permite realizar o cruzamento entre as palavras chaves nas bases de dados e biblioteca virtual com o objetivo de descrever os métodos de diagnóstico para a esquistossomose mansônica no Brasil, possibilitando compreender quais destes métodos são apropriados para cada situação. Com a disponibilização da internet e de softwares específicos, atualmente se torna mais fácil organizar as informações coletadas e todo material necessário para a conclusão da pesquisa, gerando debates e acerca do tema proposto, o que caracteriza uma revisão de literatura.

Procurou-se identificar artigos de pesquisa que descrevessem sobre os principais métodos utilizados no País para o diagnóstico da esquistossomose mansônica em áreas de baixo e alto endemismo. A busca bibliográfica dirigiu-se a um indexador: PubMed-MEDLINE, da National Library of Medicine dos Estados Unidos da América (http://www.pubmed.com.br).

Os descritores utilizados para a busca foram termos do Descritores em Ciências da Saúde (DeCS) e correspondem a "esquistossomose", "diagnóstico" e "Brasil". Os critérios de inclusão utilizados para a seleção de artigos foram: artigos completos disponíveis nas bases dados anteriormente citados, publicação em português, inglês ou espanhol e período de publicação compreendido entre janeiro de 2017 a junho de 2019.

Os critérios de exclusão foram: artigos que não estavam disponíveis de forma completa, artigos publicados fora do período compreendido, publicações escritas em línguas que não sejam o inglês, português e espanhol, artigos que não descrevessem sobre métodos de diagnóstico da esquistossomose mansônica. Após a busca utilizando os três descritores mencionados e a seleção tendo como base os critérios de inclusão foram obtidos 21 artigos, sendo que 12 destes não se encaixavam com a metodologia do tema proposto, restando ao final 09 artigos que seriam analisados posteriormente.

Após a análise completa das publicações, foi realizada uma síntese dos dados obtidos, contemplando título do artigo, autores, objetivo e principais resultados e discussão. A apresentação dos dados foi realizada de forma descritiva, procedendo-se à divisão dos dados extraídos dos artigos analisados.

\section{RESULTADOS E DISCUSSÃO}

Após a busca utilizando os três descritores mencionados e a seleção tendo como base os critérios de inclusão foram obtidos 21 artigos, sendo que 12 destes não se encaixavam com a metodologia do tema proposto. Dessa forma, foram analisados e discutidos 9 artigos científicos nacionais e estrangeiros com a temática "diagnóstico da esquistossomose mansônica". O Quadro 1 apresenta uma síntese desses estudos, trazendo informações sobre título do artigo, autor, ano de publicação, objetivo e principais resultados e conclusão. 
Quadro 1 - Caracterização dos estudos que foram selecionados na revisão integrativa. (Título, autor, ano, objetivo, principais resultados e conclusões).

\section{Título do Artigo}

\begin{tabular}{|c|} 
Título do Artigo \\
\hline Sensitivity and specificity of the circulating \\
cathodic antigen rapid urine test in the \\
diagnosis of Schistosomiasis mansoni
\end{tabular}

diagnosis of Schistosomiasis mansoni infection and evaluation of morbidity in a lowendemic areain Brazil.

\begin{tabular}{|l|c|} 
& Autor/Ano \\
\hline & FERREIRA FT, et al., 2017. \\
\hline low- & MARINHO CC, et al., 2017. \\
\hline
\end{tabular}

Morbidity of schistosomiasis mansoni in a low endemic setting in Ouro Preto, Minas Gerais, Brazil.

discrever a morbidade da esquistossomose no

Avaliar a sensibilidade e especificidade do ensaio PCO-CCA e a morbidade da esquistossomose em uma área de baixa endemicidade no Brasil.

\section{Principais Resultados e Conclusões}

No geral, o ensaio de urina POC-CCA mostrou-se um teste útil para o diagnóstico de $S$. mansoni em uma área de baixa concentração endêmica no Brasil. Formas clínicas graves de esquistossomose podem estar presentes mesmo em áreas de baixa endemicidade.

Dos 180 participantes, 97 foram examinados por Kato-Katz, com 4 $(4,1 \%)$ sendo positivos. Trinta e quatro $(22,1 \%)$ dos 154 foram positivos pelo POC-CCA. Cinco (2,8\%) das 177 examinadas por ultrassonografia tinham forma hepatoesplênica. Um deles havia passado por esplenectomia. Um (0,6\%) participante apresentou mielorradiculopatia. Formas graves de esquistossomose ainda são prevalentes em áreas de baixa endemicidade e devem ser minuciosamente investigadas.

Os resultados deste estudo demonstraram que o desempenho do

Estabelecer a prevalência de Schistosoma

Prevalence of schistosomiasis mansoni in indigenous Maxakali villages, Minas Gerais, Brazil

NACIFE MBPSL, et al. 2018. mansoni em aldeias indígenas de Maxakali, avaliando o desempenho do TF-Test $\AA$ para diagnóstico em comparação com a técnica de Kato-Katz.

Development of a laboratorial platform for diagnosis of schistosomiasis mansoni by PCR-ELISA.

SENRA C, et al., 2018.

Desenvolver uma plataforma laboratorial para liberar uma plataforma comercial utilizada no PCR-ELISA para o diagnóstico molecular da esquistossomose mansoni

O objetivo deste estudo foi avaliar o

desempenho do teste PCO-CCA em

Concordance of the point-of-care circulating cathodic antigen test for the diagnosis of intestinal schistosomiasis in a low endemicity area.
SOUSA SRM, et al., 2019. comparação com a técnica de Kato-Katz em uma área de baixa prevalência na Região

Amazônica, localizada no município de Primavera, Estado do Pará, Brasil. Kato-Katz foi superior $(p<0,05)$ ao do TF-Test $\AA$ na detecção de $S$.

Kato-Katz fol superior $(\mathrm{p}<0,05)$ ao do TF-Test $\AA$ na detecção de $S$.
mansoni. A combinação de TF-Test ${ }^{\circledR}$ e Kato-Katz resultou em um aumento na taxa de positividade de S. mansoni, demonstrando o alto risco de infecção ao qual as populações indígenas estão expostas e a importância da implementação de estratégias de controle nas aldeias de Maxakali.

A plataforma laboratorial PCR-ELISA indicou prevalência de $25,2 \%$, superior à técnica KatoKatz (18,4\%) e inferior à plataforma comercial $(30,1 \%)$. Considerando a técnica de Kato-Katz como referência, houve $97,4 \%$ e $91,1 \%$ de sensibilidade e especificidade relativas, respectivamente. A plataforma laboratorial apresentou boa precisão, desempenho diagnóstico e pode ser utilizada em substituição à plataforma comercial.

O teste imunocromatográfico tem o potencial de ser uma ferramenta importante no combate à esquistossomose, devido à sua praticidade $e$ aplicabilidade, mas deve ser aplicado com cautela em áreas de baixa prevalência e em programas que visem a eliminação desta doença. 


\begin{tabular}{|c|c|c|c|}
\hline Título do Artigo & Autor/Ano & Objetivo & Principais Resultados e Conclusões \\
\hline $\begin{array}{c}\text { Evaluation of diagnostic methods for the } \\
\text { detection of intestinal schistosomiasis in } \\
\text { endemic areas with low parasite loads: Saline } \\
\text { gradient, Helmintex, Kato-Katz and rapid } \\
\text { urine test }\end{array}$ & OLIVEIRA WJ, et al., 2018. & $\begin{array}{l}\text { Realizar testes parasitológicos extensivos de } \\
\text { até três amostras fecais e incluir um teste } \\
\text { rápido de urina (POC-CCA) em uma área de } \\
\text { prevalência moderada no Norte de Minas } \\
\text { Gerais, e avaliar o desempenho de cada teste } \\
\text { separadamente e em combinação. }\end{array}$ & $\begin{array}{l}\text { O método Kato-Katz recomendado subestimou amplamente a } \\
\text { prevalência da infecção por S. mansoni. Como o melhor desempenho } \\
\text { foi obtido com um método Helmintex modificado, essa técnica pode } \\
\text { servir como um padrão de referência mais preciso. Um número } \\
\text { estendido de lâminas de Kato-Katz em combinação com outros } \\
\text { métodos parasitológicos ou com POC-CCA foi capaz de detectar mais } \\
\text { de } 80 \% \text { dos indivíduos positivos para ovos; no entanto, o teste rápido } \\
\text { de urina (POC-CCA) produziu uma porcentagem considerável de } \\
\text { resultados falso-positivos. }\end{array}$ \\
\hline $\begin{array}{l}\text { Study of diagnostic accuracy of Helmintex, } \\
\text { Kato-Katz, and POC-CCA methods for } \\
\text { diagnosing intestinal schistosomiasis in } \\
\text { Candeal, a low intensity transmission area in } \\
\text { northeastern Brazil. }\end{array}$ & LINDHOLZ CG, et al., 2018. & $\begin{array}{l}\text { Avaliar a eficácia dos métodos de Kato-Katz } \\
\text { (KK), Helmintex (HTX) e o imunodiagnóstico } \\
\text { para a detecção do antígeno circulante catódico } \\
\text { esquistossomótico (PCO-CCA) em áreas de } \\
\text { baixa transmissão no nordeste do Brasil. }\end{array}$ & $\begin{array}{l}\text { A prevalência de esquistossomose mansoni foi determinada em } 71 \% \\
\text { com POC-CCA, } 40 \% \text { com HTX e } 11 \% \text { com KK. A maior parte das } \\
\text { cargas de ovos dos indivíduos testados (70\%) foi <1 epg, revelando } \\
\text { uma dissociação entre a prevalência e intensidade nesta localidade. } \\
\text { Portanto, os presentes resultados confirmam que o método HTX é um } \\
\text { procedimento de detecção de ovos altamente sensível e apóia sua } \\
\text { utilização como método de referência para o diagnóstico da } \\
\text { esquistossomose intestinal e para a avaliação comparativa de outros } \\
\text { testes. }\end{array}$ \\
\hline $\begin{array}{l}\text { Serological proteomic screening and } \\
\text { evaluation of a recombinant egg antigen for } \\
\text { the diagnosis of low-intensity Schistosoma } \\
\text { mansoni infections in endemic area in Brazil }\end{array}$ & MORAES VS, et al., 2019. & $\begin{array}{l}\text { A fim de desenvolver novas ferramentas de } \\
\text { diagnóstico, empregamos uma abordagem } \\
\text { proteômica para identificar biomarcadores } \\
\text { associados a respostas imunes específicas do } \\
\text { esquistossomo, na esperança de desenvolver } \\
\text { novos métodos sensíveis e específicos para o } \\
\text { imunodiagnóstico. }\end{array}$ & $\begin{array}{l}\text { A abordagem do proteoma sorológico foi capaz de identificar um novo } \\
\text { candidato ao diagnóstico. O antígeno de ovo recombinante } \\
\text { proporcionou bom desempenho em IgG-ELISA para detectar } \\
\text { indivíduos com infecções extremas de baixa intensidade (1 ovo por } \\
\text { grama de fezes). Portanto, o IgG-ELISA usando este recém- } \\
\text { identificado MEA recombinante pode ser uma ferramenta útil } \\
\text { combinada com outras técnicas em áreas de baixa endemia para } \\
\text { determinar a verdadeira prevalência da infecção pelo esquistossomo } \\
\text { que é subestimada pelo método KK. Além disso, para superar a } \\
\text { complexidade do ELISA no campo, uma segunda geração de testes de } \\
\text { diagnóstico rápido baseados em anticorpos (RDT) pode ser } \\
\text { desenvolvida. }\end{array}$ \\
\hline $\begin{array}{c}\text { Diagnosis of coinfection by schistosomiasis } \\
\text { and viral hepatitis B or C using } 1 \mathrm{H} \text { NMR- } \\
\text { based metabonomics }\end{array}$ & GOUVEIA LR. et al., 2017. & $\begin{array}{l}\text { O objetivo deste estudo foi diagnosticar a } \\
\text { fibrose periportal devido à esquistossomose } \\
\text { mansoni em pacientes com infecção crônica } \\
\text { por HBV ou HCV através de modelos } \\
\text { metabonômicos baseados em RMN. }\end{array}$ & $\begin{array}{l}\text { O modelo supervisionado construído a partir do PLS-DA apresentou } \\
\text { acurácia, sendo os valores R2 e Q2 iguais a } 100 \%, 98,1 \% \text { e } 97,5 \% \text {, } \\
\text { respectivamente. De acordo com a importância da variável no gráfico } \\
\text { de projeção, os níveis séricos de lactato foram maiores no grupo co- } \\
\text { infectado, enquanto os sinais atribuídos ao colesterol sérico HDL foram } \\
\text { mais intensos no grupo mono-infectado. } \\
\text { Os modelos metabonômicos construídos neste estudo são } \\
\text { promissores como uma ferramenta alternativa para o diagnóstico de } \\
\text { fibrose periportal por esquistossomose em pacientes com infecção } \\
\text { crônica pelo VHB ou VHC de áreas endêmicas para Schistosoma } \\
\text { mansoni. }\end{array}$ \\
\hline
\end{tabular}


Após a leitura e interpretação do conteúdo de cada artigo selecionado, foi possível a identificação de diversos tipos de métodos que podem ser utilizados para diagnóstico da esquistossomose mansônica no Brasil: Diagnóstico coprológico e Diagnóstico Sorológico e Molecular. Cabe salientar que embora sejam temáticas com abordagens diferentes, ambos se complementam e facilitam a análise da temática pesquisada.

\section{Diagnóstico Coprológico}

O método parasitológico do Kato-Katz é o recomendado pela OMS como o padrão para a detecção de infecção pelo $S$. mansoni, e se mostra bastante eficiente em indivíduos com carga parasitária alta ou média, porém, sua sensibilidade é reduzida em indivíduos com baixa carga parasitária, como consequência a prevalência real em uma localidade endêmica pode ser subestimada, levando a falhas no controle (OLIVEIRA WJ, et al., 2018).

Oliveira WJ, et al. (2018), através de um inquérito coprológico realizado em uma localidade com prevalência moderada no norte do estado de Minas Gerais, verificaram que o método de Kato-Katz detectou a infecção em 48/257 indivíduos cuja maioria apresentava uma infecção leve. Dentre os indivíduos infectados a maioria $(66,7 \%)$ tinham carga parasitária menor que 100 ovos por grama de fezes (OPG), $25 \%$ tinha infecção moderada e $8,3 \%$ estavam fortemente infectados. A prevalência subiu de 20,4 para $38,3 \%$ quando foram utilizadas duas lâminas para cada uma das três amostras coletadas. No entanto, ao comparar os resultados obtidos pelo Kato-Katz com os métodos Helmintex e Gradiente Salino, a prevalência da esquistossomose mansônica atingiu 45,9\%, o que representa um aumento de 2,3 vezes.

O método de Helmintex modificado apresentou alta sensibilidade $(86,6 \%)$ e o maior grau de concordância em relação ao padrão de referência. Lindholz CG, et al. (2018), obtiveram resultado similar ao desenvolver um estudo de base populacional envolvendo 461 indivíduos de Candeal, Sergipe, através da comparação entre três métodos, Kato-Katz, Point-of-care Circulating Cathodic Antigen (PCO-CCA) e Helmintex.,A prevalência revelada foi de $40 \%$ para Helmintex e $11 \%$ do Kato-Katz, sendo que a maior parte das cargas de ovos dos indivíduos testados foram < 1 OPG, revelando assim uma dissociação entre a prevalência e intensidade nesta localização. Oliveira WJ, et al. (2018) e Lindholz CG, et al. (2018) confirmaram que o método Helmintex se caracteriza por sua alta sensibilidade e apoiam sua utilização como um método de referência para o diagnóstico da esquistossomose mansônica e para avaliação comparativa dos outros testes.

Outro método coprológico descrito foi o Three Fecal Test (TF-Test) utilizado em um estudo conduzido por Nacife MBPSL, et al. (2018) em indígenas da aldeia Maxakali, Minas Gerais. Os resultados deste estudo permitiram concluir que ele apresentou taxa mais baixa de positividade para $S$. mansoni $(33,2 \%)$ do que a técnica de Kato-Katz (45,7\%). Vale ressaltar que a taxa de positividade obtido pelo TF-Test foi diretamente influenciado pela carga parasitária, com taxas variando de 33,9\% nos indivíduos com baixa carga parasitária a $84,2 \%$ em pessoas com uma carga elevada. Nacife MBPSL, et al. (2018) ressaltaram a importância da associação de métodos de diagnóstico para melhor detecção de indivíduos infectados, pois neste estudo o TF-Test detectou $11,5 \%$ de positividade em indivíduos que apresentaram Kato-Katz negativo, o que resultou num aumento da taxa de positividade de $45,7 \%$ para $51,9 \%$.

\section{Diagnóstico Sorológico e Molecular}

Em 2015, a OMS recomendou o uso de dois métodos combinados, PCO-CCA e Kato-Katz, cujo objetivo era monitorar a eficiência dos programas de controle em países endêmicos (SOUSA SRM, et al., 2019). Ferreira FT, et al. (2017), verificaram a sensibilidade e a especificidade do PCO-CCA no diagnóstico da esquistossomose mansônica em uma área de baixa endemicidade em Minas Gerais, o estudo foi realizado com 300 indivíduos e os resultados mostraram um total de $68,1 \%$ de sensibilidade e $72,8 \%$ de especificidade da técnica, por outro lado a sensibilidade e especificidade da técnica de Kato-Katz foram 25,6\% e 94,6\%, respectivamente. Portanto, nesse estudo, o ensaio de urina PCO-CCA provou ser um teste útil para o diagnóstico de $S$. mansoni em área de baixa endemicidade.

Marinho CC, et al. (2017), confirmaram através de um estudo realizado em Ouro Preto, Minas Gerais, que a técnica PCO-CCA possui um nível de sensibilidade maior que o Kato-Katz em áreas com baixa endemicidade, onde foram examinados 97 indivíduos através desta técnica, sendo $4 \mathrm{com}$ resultado positivo $(4,1 \%)$ e de 157 pessoas avaliadas pelo PCO-CCA, 34 foram positivas $(22,1 \%)$, enfatizando ainda mais a baixa sensibilidade da microscopia de fezes, e da necessidade de melhorar a precisão na definição da prevalência em áreas de baixa transmissão para um controle efetivo da doença. 
Sousa SRM, et al. (2019), demonstraram também em um estudo realizado em área pouco endêmica no estado do Pará que o PCO-CCA teve um índice de positividade de $23,9 \%$, enquanto que o Kato-Katz foi de $9,4 \%$, uma taxa de detecção 2,5 vezes mais elevada que o Kato-Katz. Os autores concluíram que o teste imunocromatográfico tem o potencial de ser uma importante ferramenta para combater a esquistossomose devido a sua praticidade e aplicabilidade, mas que deve ser aplicado com cautela em áreas de baixa prevalência e em programas que visam erradicar a doença de uma forma mais rápida.

Porém, Oliveira WJ, et al. (2018), verificaram que a principal desvantagem do teste de urina rápida (PCOCCA) foi uma baixa concordância com o padrão de referência, pois no estudo foi encontrado cerca de $30 \mathrm{e}$ $35 \%$ de resultados falsos positivos e falsos negativos, respectivamente.

Outros métodos com mecanismos imunológicos e moleculares envolvem a reação de antígeno-anticorpo e tem aplicação muitas vezes em inquéritos epidemiológicos, acompanhados ou não de exame coprológico. Podem ser utilizados em casos clínicos isolados, de diagnóstico difícil ou pelos métodos diretos tradicionais. Os principais são: ensaio imunoenzimático (ELISA), imunofluorescência (IF) e reação periovular (RPOV) (BRASIL, 2014).

Silva-Moraes V, et al. (2019), desenvolveram uma abordagem proteômica cujo objetivo era identificar biomarcadores associados com respostas imunológicas específicas para esquistossomose, os autores utilizaram um antígeno recombinante do ovo do parasito, e foi observado que ele possui alto desempenho em IgG-ELISA para detectar indivíduos com infecções de baixa intensidade.

Senra C, et al. (2018), desenvolveram uma plataforma laboratorial com o objetivo de comparar com uma plataforma comercial utilizado no PCR-ELISA para o diagnóstico molecular da esquistossomose. A taxa de prevalência observada por essa técnica foi de $25,2 \%$, superior que a técnica de Kato-Katz, 18,4\% e mais baixa que a plataforma comercial que foi de $30,1 \%$. Os autores concluíram que pela boa precisão da plataforma laboratorial, ela pode ser utilizada em substituição à plataforma comercial para o diagnóstico da doença.

\section{Diagnóstico por Imagem}

Para avaliação de comprometimentos orgânicos causados pela infecção por $S$. mansoni em diferentes fases da evolução da doença, os exames de imagem assumem um importante papel. Alguns exemplos utilizados no Brasil são: telerradiografia de tórax (avaliação da forma vásculo-pulmonar), o ecocardiograma (avaliação da forma vásculo-pulmonar), a ultrassonografia (US) abdominal (avaliação de forma hepatoesplênica) e a endoscopia digestiva alta e baixa (avaliação da forma hepatoesplênica) (VITORINO RR, et al., 2012).

Por conta de ser um exame não evasivo, apresentar ampla disponibilidade, possuir boa sensibilidade para detecção de nódulos sideróticos esplênicos e na mensuração do volume do fluxo na veia porta em casos onde o paciente é portador de hipertensão portal e por apresentar um excelente custo-benefício, a US abdominal tem sido considerado o método prioritário para essa forma de diagnóstico. No entanto, a desvantagem mais aparente é apresentar variação em alguns casos, principalmente, quanto à medida do diâmetro dos vasos portais, sendo este um elemento importante para a classificação da fibrose periportal (VITORINO RR, et al., 2012).

\section{CONSIDERAÇÕES FINAIS}

Neste estudo, os resultados encontrados com a análise dos artigos permitiram concluir que existem diversos métodos para diagnosticar a esquistossomose mansônica no Brasil, porém alguns destes métodos têm seu nível de sensibilidade reduzido quando são utilizados em localidades pouco endêmicas, como é o caso do Kato-Katz, que apesar de ser o padrão ouro preconizado pela OMS, em alguns estudos observou-se a ocorrência de diversos falsos negativos quando comparado com outras técnicas. Também foi observada a necessidade de aplicação de mais de um método de diagnóstico para aumentar o nível de especificidade e sensibilidade, pois há risco também de ocorrência de resultados cruzados com outras parasitoses. Diversos métodos coprológicos, imunológicos e moleculares estão surgindo e se mostram promissores para um diagnóstico bastante eficaz, portanto, espera-se que políticas públicas sejam desenvolvidas com o objetivo de se realizar um controle mais rigoroso da doença no país. 


\section{REFERÊNCIAS}

1. BARBOSA CS, GOMES ECS. Manual prático para o diagnóstico e controle da esquistossomose. Recife: Editora Universitária da Universidade Federal de Pernambuco; 2017: 86p.

2. BRASIL. Ministério da Saúde. Informe técnico: "Campanha Nacional de Hanseníase, Verminoses, Tracoma e Esquistossomose. 5ำ ed. Brasília: MS; 2017. 17 p.

3. BRASIL. Ministério da Saúde. Inquérito Nacional de Prevalência da Esquistossomose mansoni e Geo-helmintoses. Belo Horizonte: CPqRR, 2018.

4. BRASIL. Ministério da Saúde. Vigilância da Esquistossomose Mansoni: Diretrizes Técnicas. 4ํo ed. Brasília: MS; 2014. $144 \mathrm{p}$.

5. CARVALHO OS, et al. Distribuição geográfica dos hospedeiros intermediários do Schistosoma mansoni nos estados do Paraná, Minas Gerais, Bahia, Pernambuco e Rio Grande do Norte, 2012-2014. Revista de Epidemiologia e Serviços de Saúde, 2018; 27(3).

6. COSTA CS, et al. Programa de Controle da Esquistossomose: avaliação da implantação em 65 três municípios da Zona da Mata de Pernambuco, Brasil. Saúde Debate. 2017; 41(Especial): 229-241.

7. DEININGER LSC, et al. Tendência das proporções de casos notificados de Esquistossomose nos municípios endêmicos da Paraíba. Revista Saúde (Sta. Maria), 2018; 44(3).

8. FERREIRA FT, et al. Sensitivity and specifity ofthe circulating cathodic antigen rapid urine test in the diagnosis of Schistosomiasis mansoni infection and evaluation of morbidity in a low- endemic area in Brazil. Rev Soc Bras Med Trop, 2017; 50(3): 358-364.

9. GANDASEGUI J, et al. A field survey using LAMP assay for detection of Schistosoma mansoni in a low-transmission area of schistosomiasis in Umbuzeiro, Brazil: Assessment in human and snail samples. Plos Negl Trop Dis. 2018; 12(3). e0006314

10. GOMES ECS, et a. Transmissão urbana da esquistossomose: novo cenário epidemiológico na Zona da Mata de Pernambuco. Rev Bras Epidemiol, 2016; 19(4): 822-834.

11. GOUVEIA LR, et al. Diagnosis of coinfection by schistosomiasis and viral hepatitis B or C using $1 \mathrm{H}$ NMR-based metabonomics. PLoS ONE, 2017; 12(8).

12. LINDHOLZ CG, et al. Study of diagnostic accuracy of Helmintex, Kato-Katz, and PCO-CCA methods for diagnosing intestinal schistosomiasis in Candea, a low intensity transmission area in northeastern Brazil. PLOS Neglected Tropical Diseases, 2018; 12(3).

13. MARINHO CC, et al. Morbidity of schistosomiasis mansoni ina low endemic setting in Ouro Preto, Minas Gerais, Brazil. Rev Soc Bras Med Trop, 2017; 50(6): 805-811.

14. MASSARA CL, et al. Caracterização de materiais educativos impressos sobre esquistossomose, utilizados para educação em saúde em áreas endêmicas no Brasil. Revista de Epidemiologia e Serviços de Saúde, 2016; 25(3).

15. MELO AGSM, et al. Esquistossomose mansônica em famílias de trabalhadores da pesca de área endêmica de Alagoas. Escola Anna Nery, 2019; 23(1).

16. MORAES VS, et al. Serological proteomic screening and evaluation of a recombinant egg antigen for the diagnosis of low-intensity Schistosoma mansoni infections in endemic area in Brazil. PLOS Neglected Tropical Diseases, 2019; 13(3).

17. MOURA BRS, et al. Análise temporal dos casos de esquistossomose em municípios endêmicos na Paraíba, Brasil. Interfaces Científicas - Saúde e Ambiente, 2018; 7(1), 61-70.

18. NACIFE MBPSL, et al. Prevalence of schistosomiasis mansoni in indigenous Maxakaii villages, Minas Gerais, Brazil. Revista do Instituto de Medicina Tropical de São Paulo, 2018; 60(26).

19. NEVES DP. Parasitologia Humana. São Paulo: Atheneu; 2002; 501p.

20. OLIVEIRA WJ, et al. Evaluation of diagnostic methods for the detection of intestinal schistosomiasis in endemic areas with low parasite loads: Saline gradient, Helmintex, Kato-Katz and rapid urine test. PLOS Neglected Tropical Diseases, 2018; 12(2).

21. ROCHA TJM, et al. Aspectos epidemiológicos dos casos de infecção pelo Schistosoma mansoni em municípios do Estado de Alagoas, Brasil. Rev Pan-Amaz Saúde, 2016; 7(2): 27-32.

22. SARVEL AK, Oliveira AA, Silva AR, Lima AC, Katz N. Evaluation of a 25-year program for the control of schistosomiais mansoni in a endemic area in Brazil. Plos Negl Trop Dis. 2011; 5(3): e990.

23. SENRA C, et al. Development of a laboratorial platform for diagnosis of schistosomiasis mansoni by PCR-ELISA. BMC Res Notes,2018; 11(455).

24. SIQUEIRA LMV. Diagnóstico da esquistossomose mansoni em áreas de baixa transmissão: avaliação de diferentes técnicas (Kato-Katz, Gradiente Salínico, PCR-ELISA e qPCR) antes e após intervenção terapêutica. Tese (Doutorado em Ciências da Saúde) - Fundação Oswaldo Cruz, Belo Horizonte, 2015: 122p..

25. SIQUEIRA LMV, et al. Evaluation of parasitological and molecular techniques for the diagnosis and assessment of cure of schistosomiasis mansoni in a low transmission area. Mem Inst Oswaldo Cruz. 2015; 110(2): 209-214.

26. SILVA-MORAES V, et al. Serological proteomic screening and evaluation of a recombinant egg antigen for the diagnosis of low-intensity Schistosoma mansoni infections in endemic area in Brazil. PLoS Negl Trop Dis, 2019; 13(3).

27. SOUSA SRM, et al. Concordanceof the point-of-care circulating cathodic antigen test for the diagnosis of intestinal schistosomiasis in a low endemicity area. Infectious Diseases of Poverty. 2019; 8(37).

28. SOUZA GGS, CERQUEIRA EJL. Ocorrência de esquistossomose mansônica no estado da Bahia - Brasil no período de 2007 a 2014. Revista Diálogos \& Ciências, 2017; 40(17): 81-100.

29. TERRA MR, et al. Levantamento epidemiológico de Esquistossomose Mansoni em Londrina-PR. Revista UNINGÁ, 2018; 55(3): 208-217.

30. VITORINO RR, et al. Esquistossomose mansônica: diagnóstico, tratamento, epidemiologia, profilaxia e controle. Rev Bras Clin Med. 2012; 10(1): 39-45. 